\title{
Synergism of the combination of Rhopalurus junceus scorpion venom with conventional cytostatics in the ct 26 tumor cell line.
}

\author{
Arianna Yglesias-Rivera ${ }^{*}$, Ana Mary Sánchez-Mamposo², Alexis Díaz-García1, Hermis Rodríguez- \\ Sánchez ${ }^{3}$ \\ ${ }^{1}$ Research Department, Laboratories of Biopharmaceuticals and Chemicals Productions, Havana, Cuba \\ ${ }^{2}$ Production Department, Finlay Institute, Havana, Cuba \\ ${ }^{3}$ Microbiology Department, Tropical Medicine Institute "Pedro Kourí”, Havana, Cuba
}

\begin{abstract}
Introduction: The endemic scorpion venom of Cuba, Rhopalurus junceus (R. junceus), decreases the viability of tumor cells of epithelial origin and has no cytotoxic effect on normal cells. However, its antineoplastic effect on murine colon tumor cells and the type of pharmacological interaction of its combination with conventional chemotherapeutic agents used in the clinic for the treatment of colon cancer have not been evaluated.

Objective: To determine the potentiality of the $R$. junceus scorpion venom to increase the cytotoxic effect of conventional cytostatics on colon tumor cells.

Materials and methods: CT26 murine colon tumor cells were treated simultaneously at a constant rate of concentrations equal to or lower than the mean inhibitory concentration (IC50) of the venom of the scorpion R. junceus and the cytostatics: doxorubicin (DOX), cisplatin (CDPP) and paclitaxel (PTX), respectively. Cell viability was determined by the MTT assay, after 72 hours of incubation and the determination of apoptotic cell formation was determined by DAPI staining after 24 hours of combination with $1 / 2$ of the IC50. The combination and dose reduction rate was determined by the Compusyn software.

Results: The combination of venom with CPDX, PTX, and DOX, paclitaxel and doxorubicin significantly reduced the viability of the CT26 tumor line, compared to individual treatments. The type of drug interaction of said combination was synergistic at high concentrations. Individual treatment with $1 / 2$ of the IC50 of $R$. junceus scorpion venom or with conventional cytostatics and the combination of each cytostatic with the venom induced morphological changes characteristic of cell death by apoptosis.

Conclusion: R. junceus scorpion venom in combination with CDDP, PTX, and DOX paclitaxel, doxorubicin and cisplatin increases the cytotoxicity of these chemotherapeutic agents on colon tumor cells.
\end{abstract}

Keywords: Rhopalurus junceus scorpion venom, Colon cancer cells, Conventional cytostatic, Synergic effect and apoptosis.

Accepted on November 27, 2019

\section{Introduction}

Among the types of tumors with the greatest impact worldwide are colorectal cancer (CRC), which is the third in incidence and the second in mortality [1,2]. Among the chemotherapeutic agents most used against CRC are: cisplatin (CDDP) [3], paclitaxel (PTX) [4] and doxorubicin [5]. However, the benefits for cancer patients in whom antineoplastic agent therapy is used are limited, due to the progressive resistance that tumor cells acquire to this treatment and the toxicity it causes on normal cells [4].

Plant-derived products have a beneficial effect in the treatment of cancer, which have been demonstrated in studies conducted with Curcuma longa [6,7], manguiferin [8] and alcoholic extract of Allium atroviolaceum [9]. Natural products provide a large number of molecules with cytotoxic and apoptogenic activities against various types of tumors including CRC [10]. However, these natural products have been used primarily in combination with conventional chemotherapeutic agents, which increases the effectiveness of cancer treatment and reduces the side effects caused by antineoplastic drugs [4].

The alcoholic extract of Allium atroviolaceum in combination with DOX revealed a significant reduction in IC50 and led to a synergism relationship between the drugs [9]. While the combination of manguiferin with non-cytotoxic concentrations 
of CDDP and 5-FU significantly decreased the viability of CT26 colon tumor cells with respect to the individual treatment of the chemotherapeutic agent [8]. Other examples of greater effectiveness of the combined therapy with respect to the individual, were evidenced in studies of genistein combination with CDDP and also of geraniol with 5-FU [11].

The molecules and peptides from the scorpion venom can be used to develop highly potent anticancer, antimicrobial and many other effective drugs. The Chinese, Indian, and African traditional medicines have made a use of scorpions and their venoms for thousands of years. The inhibition of cancer progression and induce apoptosis have shown in an increasing number in vitro and in vivo studies with scorpion venoms [1].

Rhopalurus junceus (R. junceus) scorpion venom is endemic from Cuba, has been used in traditional medicine as an antiinflammatory, analgesic and antitumor drug. This scorpion is an endemic species of Cuba that belongs to the Buthidae family. Previous studies have shown that this scorpion venom exerts a selective cytotoxic effect against cancer cell lines of epithelial origin without affecting normal cells [12]. In addition, the antineoplastic effect of scorpion venom includes the induction of apoptosis in cervical-uterine cancer (HeLa) cell lines [12] and MDA-MB-231 metastatic breast cancer [13]. At present, the effect of the poison in combination with conventional cytostatics on a cervical-uterine cancer cell line has been evaluated where it was demonstrated that it is capable of potentiating the cytotoxic effect of 5-FU, CDDP and DOX on the HeLa cell line [14]. This evidence opens the possibility of investigating the effect of R. junceus scorpion venom and its combination with chemotherapeutic agents in other tumor lines. The objective of the present study is to determine the potentiality of the $\mathrm{R}$. junceus scorpion venom to increase the cytotoxic effect of conventional cytostatics on colorectal cancer cells.

\section{Materials and Methods}

\section{Reagents}

Fetal bovine serum (FBS) was purchased from Hyclone. The 3[4,5-dimethylth-iazol-2-yl] -2,5-di-phenyltetrazolium bromide (MTT) reagent, dime-thyl sulfoxide (DMSO), cisplatin (CDDP, C2210000), doxorubicin (DOX, D1515), and paclitaxel (PTX, T7402) were purchased from Sigma-Aldrich (St Louis, MO, USA).

\section{Venom source}

Adult Rhopalurus junceus scorpions, collected in Cienfuegos province, were kept in captivity for at least 1 month before venom extraction. Recent experiments demonstrated that lesser time of venom collection influence the venom composition and biological activity (unpublished results). Scorpions were maintained under Bioterium conditions, in individual plastic cages at $22.8^{\circ} \mathrm{C}$ and $76 \%$ relative humidity in laboratories belonging to The Entrepreneurial Group of Biopharmaceuticals and Chemistries Productions (LABIOFAM). Water was given ad libitum using a cotton disc and animals were fed once a week. Venom from scorpions kept alive was obtained by electrical stimulation. This method has been recognized to cause fewer traumas, do not damage animal integrity and permits the obtaining best yields compared to other methods [15-17]. The obtaining, bioterium condition, management of scorpion colonies and collection of venom have been approved by the Ministry of Science, Technology and Environment of Cuba (CITMA 20/2016). Venom was dissolved in distilled water, centrifuged at $15000 \mathrm{rpm}$ for $15 \mathrm{~min}$ and supernatant was filtered by $0.2 \mu \mathrm{m}$ syringe filter and stored at $-20^{\circ} \mathrm{C}$ until used. The protein content was calculated by the method of Lowry modified [17].

\section{Cell lines and culture}

The cell line used in the experiments was CT26 (murine colon adenocarcinoma ATCC CRL-2638 ${ }^{\mathrm{TM}}$ ). These cells at passage seven were routinely maintained in Eagle' $\mathrm{s}$ Mini-mum Essential Medium in Earle' $\mathrm{s}$ BSS with non-essential amino acids, 90\% (w/v) containing L-glutamine (Sigma-Aldrich, St. Louis, MO, USA) and supplemented with $10 \%$ heat inactivated fetal bovine serum, $100 \mu \mathrm{g} / \mathrm{mL}$ of penicillin and $100 \mu \mathrm{g} / \mathrm{mL}$ of streptomycin. This cell line was maintained in a humidified atmosphere containing $95 \%$ air $/ 5 \% \mathrm{CO}_{2}$ at $37^{\circ} \mathrm{C}$. The growth medium was replaced every three days. At day seven, the cells were trypsinized (Sigma-Aldrich, St. Louis, MO, USA) and seeded at a density of $2 \times 10^{5}$ cells $/ \mathrm{mL}$ in 96 multiwell flat bottom plates (Costar Corning, Rochester, NY, USA) in $50 \mu \mathrm{L}$ of medium/well and incubated overnight to recovery and cell adhesion in a humidified atmosphere of $5 \%(\mathrm{v} / \mathrm{v}) \mathrm{CO}_{2}$ at $37^{\circ} \mathrm{C}$ for 24 hours.

\section{In vitro cell viability assay (MTT assay)}

The effect of individual or combined treatment of conventional cytostatics: cisplatin (CDDP), doxorubicin (DOX) and paclitaxel (PTX), on CT26 cell viability was determined by the MTT assay (Mosmann, 1983). After 24 hours in a humidified atmosphere of $5 \%(\mathrm{v} / \mathrm{v}) \mathrm{CO}_{2}$ at $37^{\circ} \mathrm{C}, 50 \mu \mathrm{L}$ of each drug alone or combined simultaneously at constant ratio with scorpion venom were applied to the wells. In CT26 cells different drug concentrations were used for $\operatorname{CDDP}\left(1.9-30 \times 10^{-3} \mathrm{mg} / \mathrm{mL}\right)$, DOX $\left(34.8-556 \times 10^{-3} \mathrm{mg} / \mathrm{mL}\right), \operatorname{PTX}\left(0.0005-5 \times 10^{-3} \mathrm{mg} / \mathrm{mL}\right)$ and R. junceus scorpion venom $\left(0.063^{-1} \mathrm{mg} / \mathrm{mL}\right)$. These concentrations evaluated in vitro of the $\mathrm{R}$. junceus scorpion venom agree with those previously evaluated by our working group $[12,13]$.

Once the mean inhibitory concentration of each of the compounds (IC50) was determined at constant rate, the IC50 of R. junceus with the IC50 of CDDP/DOX/PTX and four double dilutions were made and incubated for 72 hours to determine cell viability.

Cells with culture medium and without treatment were used as un-treated growth control. Three wells were included in each concentration evaluated for individual and combined treatment. After treatment for 72 hours, $10 \mu \mathrm{L}$ of $5 \mathrm{mg} / \mathrm{mL}$ of sterile MTT 

cell line

was added per well and cultivated for additional 3 hours. The supernatant was carefully removed, $150 \mu \mathrm{L}$ DMSO was added per well and shaken for 15 minutes at $37^{\circ} \mathrm{C}$. The absorbance was measured at $560 \mathrm{~nm}$ with $630 \mathrm{~nm}$ as reference using a micro plate reader ELISA (MRX Revelation Dynex Technologies, Denkendorf, Germany). Absorbance from untreated cells was considered as $100 \%$ of growth and used for viabil-ity calculation. The $\%$ viability was calculated, using the formula: \%viability=A560 - $630 \mathrm{~nm}$ of treated cells/A560 $630 \mathrm{~nm}$ of control cells $\times 100 \%$. The IC50 values from cancer cells were determined by interpolation of trend line from linear regression curve obtained in the GraphPad Prism version 5.01 for Windows program (GraphPad Software, San Diego California, USA), based on the percentage values of viable cells for each of the concentrations evaluated. The experiments were performed at least three times.

\section{Phase contrast microscopy}

After treatments, cells were washed with PBS and morphological changes in culture were then observed under microscope IX-71 (Olympus Corporation, Tokyo, Japan). Images were captured using the camera DP-72 (Olympus Corporation, Tokyo, Japan) and 10X objectives.

\section{Evaluation of drug interaction}

For analysis of drug interactions were deter-mined two parameters that describe the interaction in a given combination: the combination index (CI) and the dose reduction index (DRI). The CI and the DRI were generated automatically using CompuSyn software (version 1.0; ComboSyn, Inc., Paramus, NJ, USA), as previously was described by Chou (2006). The $\mathrm{CI}<1$ indicates synergism, $\mathrm{CI}=1$ or close to 1 indicates additive effects, and $\mathrm{CI}>1$ indicates antagonism. DRI $>1$ and $<1$ indicate favorable and not favorable dose-reduction; DRI $=1$ indicates no dose-reduction.

The CI and DRI were calculated in relation to the fraction of affected cells $(\mathrm{Fa})$ at any given experimental point. Fa was calculated as follows: (100 - \%Viable Cells)/100.

\section{DAPI staining by fluorescence microscopy}

The cells are detached by treatment with a $0.25 \%$ solution of trypsin-EDTA (Sigma-Aldrich, St. Louis, MO, USA) and prepared at a concentration of $1 \times 10^{5}$ cells $/ \mathrm{mL}$ in 24-well plates of polystyrene flat bottom (Costar Corning, Rochester, $\mathrm{NY}$, USA) and incubated in a $5 \% \mathrm{CO}_{2}$ atmosphere at $37^{\circ} \mathrm{C}$ for 24 hours. Subsequently, they are incubated for 24 hours with IC25 and IC50 of R. junceus, CDDP, DOX, PTX, CDDP $+\mathrm{R}$.junceus, $\mathrm{DOX}+\mathrm{R}$. junceus and $\mathrm{PTX}+\mathrm{R}$. junceus, respectively. The next day, the culture medium was removed from the wells and $500 \mu \mathrm{L}$ of fixation solution (acetic acid/ methanol) (1: $2 \mathrm{~mL}$ ) was added to the plate for $2 \mathrm{~min}$. Once the fixing agent was removed, the plate was washed with distilled water twice and the same initial operation was repeated. Subsequently, $300 \mu \mathrm{L}$ of the DAPI dye (Sigma, USA) was added to each well at a final concentration of $1 \mu \mathrm{g} / \mathrm{mL}$. The analysis of apoptotic cells was performed using a fluorescence microscope (Olympus IX-71, Japan) using the $480 \mathrm{~nm}$ filter. The images were captured using the DP-72 camera (Olympus Corporation, Tokyo, Japan) and 10xmagnification. The experiments were performed in triplicate and repeated 3 times.

\section{Statistical Analysis}

Results were presented as the mean \pm standard error media (SEM). Statistical analysis was performed by two-way ANOVA, post-test: Bonferroni, using GraphPad Prism version 5.01 for Windows, (GraphPad Software, and San Diego California, USA). Significant differences were considered for $\mathrm{p}<0.05$.

\section{Results}

The effect of the individual treatment on the viability of the CT26 of the R. junceus scorpion venom and the conventional cytostatics CDDP, DOX and PTX after 72 hours of incubation was evaluated (Figure 1). From the concentration of 0.25 $\mathrm{mg} / \mathrm{mL}$ of scorpion venom, cell viability significantly decreased $(p<0.05)$, respect to control cells treated with only culture medium (Figure 1A). While, these statistically significant differences were reached from $7.5 \times 10^{-3} \mathrm{mg} / \mathrm{mL}$, $69.6 \times 10^{-3} \mathrm{mg} / \mathrm{mL}$ and $0.5 \times 10^{-3} \mathrm{mg} / \mathrm{mL}$ of CDDP, DOX and PTX, respectively (Figures 1B-1D). For all the treatments evaluated, the decreased in viability was dependent of the concentration used. The IC50 was R. junceus $>$ DOX $>$ CDDP $>$ PTX (Table 1).
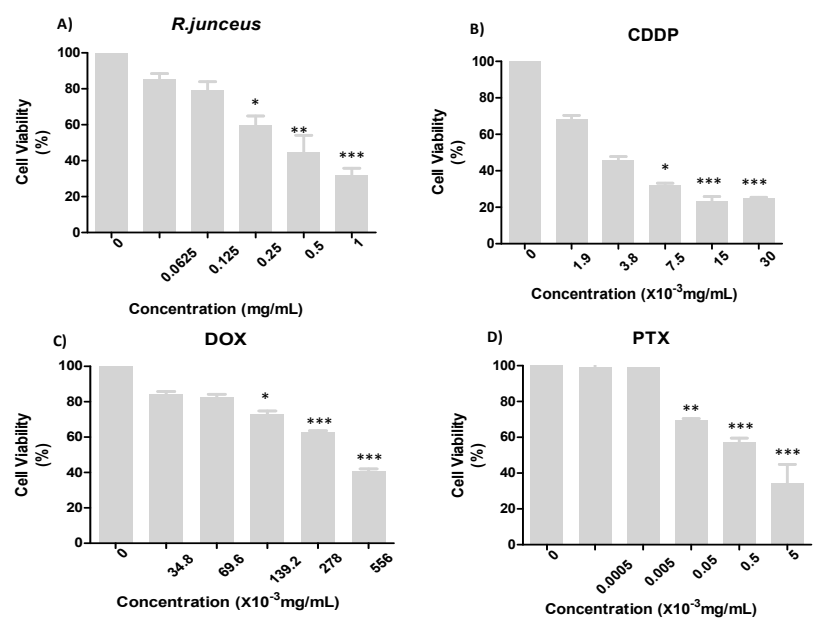

Figure 1. Effect of R. junceus scorpion venom, CDDP, DOX and PTX on the viability of CT26.

The cells were incubated for 72 hours with R. junceus (A), CDDP (B), DOX (C) or PTX (D). The percentage of cell viability was measured by MTT cytotoxicity assay. Three independent experiments were performed with three replicates each one. Statistical analysis was performed using the nonparametric Kruskall Wallis method and multiple comparisons by the Dunn test. The differences were considered significant when $\mathrm{p}<0.05 \quad(*), \mathrm{p}<0.01 \quad(* *)$ and $\mathrm{p}<0.001 \quad(* * *)$. The 
statistical package of GraphPad version 5.01 was used (Figure 2).

Table 1. Average values of IC50 and the standard desviation of simple treatments with $R$. junceus scorpion venom and conventional cytostatics CDDP, DOX and PTX.

\begin{tabular}{lll}
\hline Treatments & IC50 (mg/ml) & SD \\
\hline R. junceus & 0.72 & 0.3 \\
\hline CDDP & $9 \times 10^{-3}$ & $0.31 \times 10^{-3}$ \\
\hline DOX & $348 \times 10^{-3}$ & $67 \times 10^{-3}$ \\
\hline PTX & $1 \times 10^{-3}$ & $0.27 \times 10^{-3}$ \\
\hline
\end{tabular}

The percentages of viable cells were statistically significant differences between the individual treatment of CDDP with respect to its combination with $\mathrm{R}$. junceus scorpion venom for $1 / 16 \operatorname{IC} 50(\mathrm{p}<0.01), 1 / 8 \operatorname{IC} 50(\mathrm{p}<0.001), 1 / 4 \operatorname{IC} 50(\mathrm{p}<0.01), 1 / 2$ IC50 $(\mathrm{p}<0.01)$ and the IC50 $(\mathrm{p}<0.01)$ (Figure $3 \mathrm{~A})$. While for the combination of venom with DOX (Figure $3 \mathrm{~B}$ ) and PTX (Figure 3C), respectively, only significant statistically differences were observed for the combination of $1 / 2$ IC50 $(\mathrm{p}<0.01)$ and IC50 $(\mathrm{p}<0.001)$.
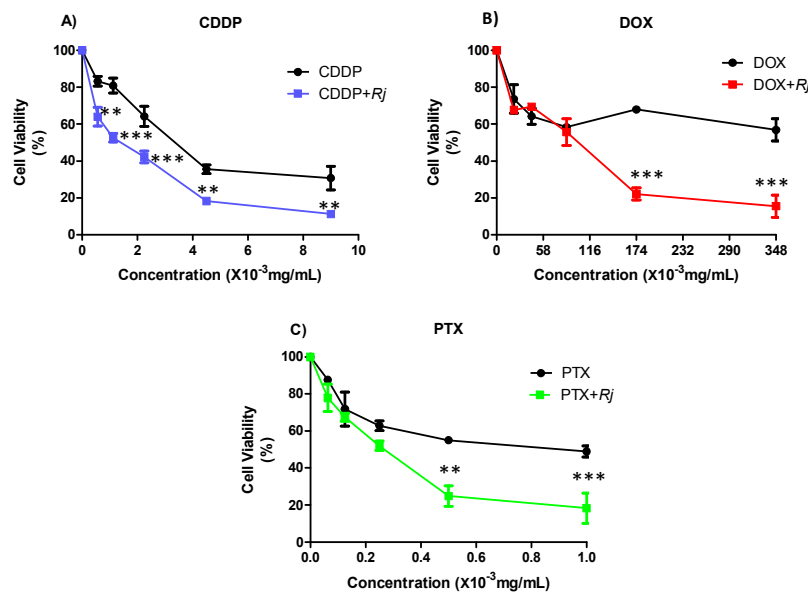

Figure 2. Effect of $C D D P+R$. junceus, $D O X+R$. junceus and $P T X+R$. junceus with respect to monotherapy on CT26 viability.
The graphs show the mean $\pm \mathrm{SD}$ of the percentage of viable cells of the cells treated with CDDP (A), DOX (B), PTX (C) and (D) R. junceus and the combination with $1 / 16$ IC50 R. junceus+1/16 IC50 CDDP/DOX/ PTX, 1/8 IC50 R. junceus+1/8 IC50 CDDP/DOX/PTX, $1 / 4$ IC50 R. junceus+1/4 IC50 CDDP/ DOX/ PTX, 1/2 IC50 R. junceus+1/2 IC50 CDDP/DOX/PTX and IC50 R. junceus+IC50 CDDP/ DOX/PTX. Three independent experiments were performed with 3 replicates each one. The differences were considered significant when $\mathrm{p}<0.05\left(^{*}\right)$, $\mathrm{p}<0.01(* *)$ and $\mathrm{p}<0.001(* * *)$. The statistical package GraphPad version 5.01 was used.

In Table, the CI and DRI values corresponding to R. junceus venom combinations with $\mathrm{CDDP} / \mathrm{DOX} / \mathrm{PTX}$ were shown. In all the combinations evaluated for each of cytostatics, the $\mathrm{CI}$ was less than 1 , for that reason the type of pharmacological interaction between the drugs is synergistic, except for the combination of $1 / 16$ and $1 / 8$ of IC50 of R. junceus scorpion venom with PTX. While only moderate synergism was obtained in the combination of the $1 / 2$ IC50 of the CDDP with the R. junceus scorpion venom. For the combination of the $1 / 4$ IC50 of R. junceus scorpion venom with DOX a strong synergism was obtained. Meanwhile, a very strong synergism was obtained for the combination of $1 / 2$ and IC 50 of R. junceus with PTX. On the other hand, for those treatments where the CI was less than 1, DRI values greater than 1 were obtained.

The DRI values for the combined treatment of the CDDP with $R$. junceus scorpion venom indicate that with this combination it is possible to reduce the concentration of CDDP from 2 to 3.4 times. Similarly, the combination of DOX with R. junceus scorpion venom promotes a considerable reduction in concentration from 3.1 to 5642.2 times. While another significant dose reduction was achieved with the combination of PTX with R. junceus scorpion venom, since it was possible to reduce 73845.2 times, compared to an individual treatment, to achieve the same effect, and was shown in Table 2.

Table 2. Average values of CI and DRI generated by the Compusyn 1.0 program; as well as determination of the degree of drug interaction, reported by Chou et al. [18].

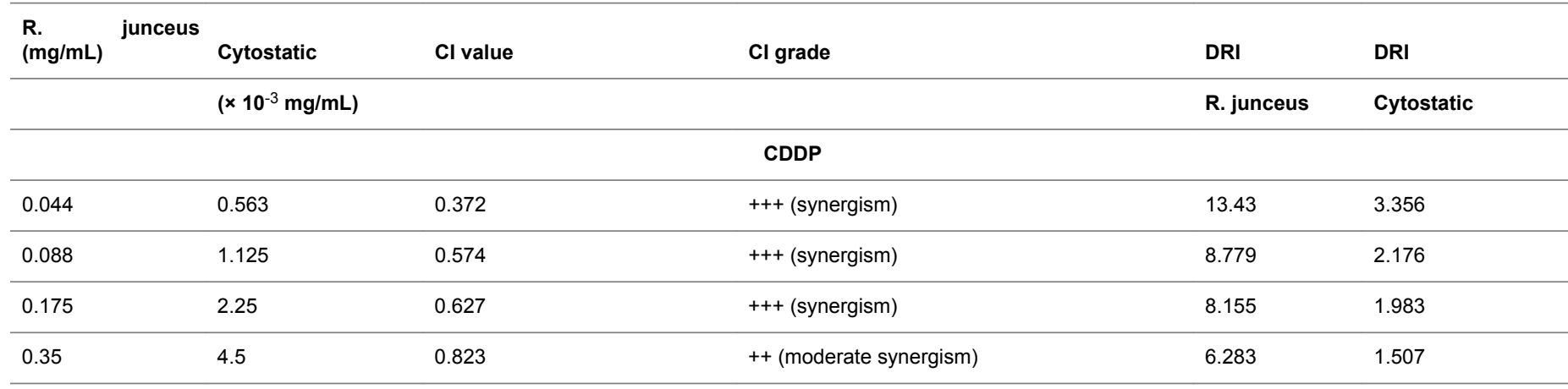


Synergism of the combination of Rhopalurus junceus scorpion venom with conventional cytostatics in the ct26 tumor cell line

\begin{tabular}{|c|c|c|c|c|c|}
\hline 0.7 & 9 & 0.627 & +++ (synergism) & 8.471 & 1.963 \\
\hline \multicolumn{6}{|l|}{ DOX } \\
\hline 0.044 & 21.75 & 0.509 & +++ (synergism) & 5.235 & 3.149 \\
\hline 0.088 & 43.5 & 0.509 & $+++($ synergism $)$ & 5.235 & 3.149 \\
\hline 0.175 & 87 & 0.238 & ++++ (strong synergism) & 4.207 & 1989.28 \\
\hline 0.35 & 174 & 0.442 & +++ (synergism) & 2.266 & 1804.43 \\
\hline 0.7 & 348 & 0.674 & +++ (synergism) & 1.483 & 5642.24 \\
\hline \multicolumn{6}{|c|}{ PTX } \\
\hline 0.044 & 0.063 & 22.38 & -----(very strong antagonism) & 1.125 & 0.046 \\
\hline 0.088 & 0.125 & 3.988 & ---- (strong antagonism) & 1.515 & 0.347 \\
\hline 0.175 & 0.25 & 0.588 & +++ (synergism) & 2.602 & 4.905 \\
\hline 0.35 & 0.5 & 0.087 & +++++ (very strong synergism) & 11.629 & 1025.23 \\
\hline 0.7 & 1 & 0.028 & +++++ (very strong synergism) & 35.681 & 73845.2 \\
\hline
\end{tabular}

Note: Cl: combination index, DRI: dose reduction index.

$<0.1$ : very strong synergism, $0.1-0.3:++++$ strong synergism; $0.3-0.7:+++$ synergism; $0.7-0.85:++$ moderate synergism; 3.3-10: ---- strong antagonism; >10: ----- very strong antagonism.

The morphological changes induced by the lowest concentration of the combined treatment of the scorpion venom
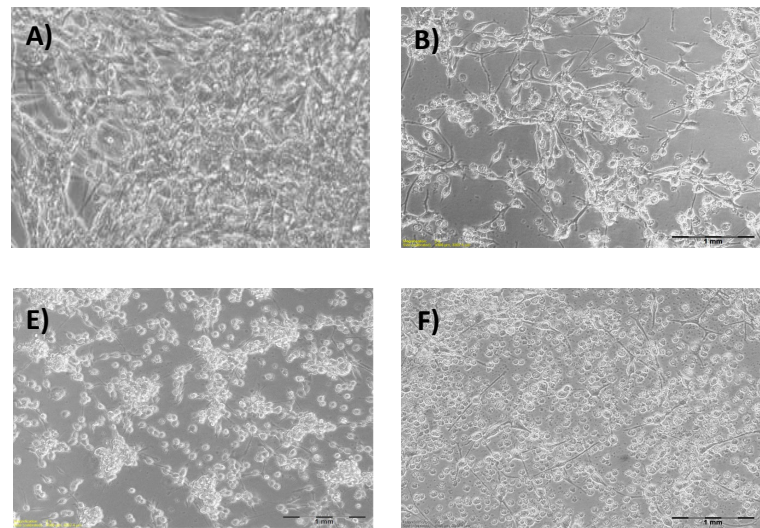
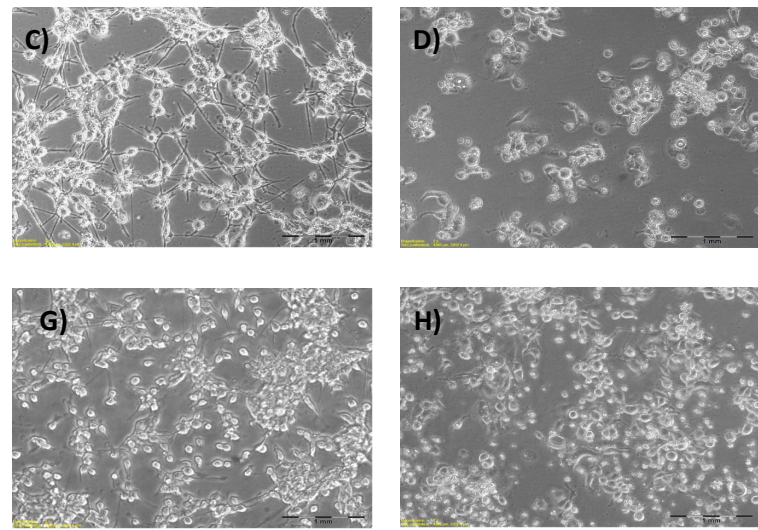

R. junceus with the conventional cytostatics CDDP, DOX and PTX that induced a significant reduction of CT26 viability were shown in Figure 3 . Combined treatment of R. junceus scorpion venom with conventional cytostatics resulted in superior loss of membrane integrity, compared to monotherapy (Figure 4).

Figure 3. Morphology of CT26 treated with the combination of R. junceus scorpion venom with CDDP, DOX and PTX. The photographs show the effect on the treatment monolayer for 72 hours with 100\% cell viability control (A), 1/2 IC50 of CDDP (B), DOX (C), PTX (D), R. junceus (E), $C D D P+R$. junceus $(F), D O X+R$. junceus $(G), P T X+R$. junceus $(G)$. The images were captured using the DP-72 camera (Olympus Corporation, Tokyo, Japan). The experiments were performed in triplicate and repeated 3 times.

To determine the effects of the simple and combined treatment of R. junceus scorpion venom and conventional cytostatics CDDP, DOX and PTX on the events of cell death in the CT26 tumor line, the DAPI marker was used by fluorescence microscopy with the $1 / 2$ IC50 and IC50 of each treatment used. In Figure 4 , it was observed that for $1 / 2$ IC50 of the individual or combinated treatment of $\mathrm{R}$. junceus scorpion venom and conventional cytostatics, unlike what occurs in untreated cells, the presence of nuclear staining was highly detected.
Condensed and the formation of apoptotic bodies, which were detected by marking with DAPI, these morphological changes characterize a cell death by apoptosis. However, this staining was observed with less intensity when the cells were incubated with the $1 / 2$ IC50 of each of the treatments (data not shown). 


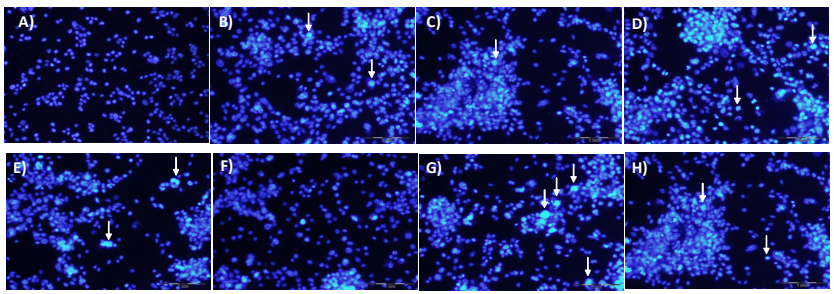

Figure 4. DAPI staining of CT26 cells treated with $1 / 2$ IC50 of individual and combined treatments. The CT26 cell line was incubated for 24 hours with the $1 / 2$ IC50 of R. junceus (B), CDDP $(C)$, $C D D P+R$. junceus (D), DOX (E), DOX+R. junceus $(F), P T X(G)$ and $P T X+R$. junceus. White arrows indicate the presence of apoptotic cells. The images were captured using the DP-72 camera (Olympus Corporation, Tokyo, Japan) and 10x magnifications.

\section{Discussion}

Preclinical studies with scorpion venom for cancer treatment have been the focus of researchers in recent years [1]. Individual treatment [12,13] and combined treatment [14] of the endemic scorpion venom of Cuba, R. junceus, decreases the viability of tumor cells of epithelial origin. However, its individual and combined effect with conventional cytostatic in the viability and morphology over a murine colon tumor line is unknown.

In the present study, R. junceus scorpion venom significantly reduces the viability of the CT26 tumor line from a total protein concentration of $0.25 \mathrm{mg} / \mathrm{mL}$, compared to untreated cells. The sensitive of the CT26 tumor line to the action of R. junceus scorpion venom increases the number of tumor lines of epithelial origin previously described [12] on which this scorpion venom reduces its cell viability. Besides, the IC50 obtained coincides with the one reported for the breast tumor line MDA-MB-231 [12,13]. Besides, this sensibility of the CT26 cell line to the action of scorpion venom was previously demonstrated for the Hemiscorpius lepturus scorpion venom. This scorpion exerts a potent cytotoxic effect on CT26 colon cancer and has a low toxicity for normal Vero cells, probably has a specific effect on other colon cancer cells and can become an effective therapeutic strategy in the treatment of colon cancer $[19,20]$.

The results obtained with the individual treatment of conventional cytostatics in the determination of cell viability agree with the reported in the literature [8,21]; although there are some differences in the experimental conditions in which the trial was performed. In the present study of the three chemotherapeutic agents used, DOX presented the highest resistance to conventional treatment. The IC50 value obtained for the DOX is consistent with that obtained by Przybyszewska and collaborators in the same tumor line, where it reports that the DOX administered as an individual treatment is not sufficient to completely eradicate the CRC [21]. The PTX of the drugs evaluated had the main effect in the reduction of CT26 cell viability. This cytostatic is widely used in the treatment of gastrointestinal tumors [4].
The reduction in the viability of the CT26 tumor line treated with the R. junceus scorpion venom combination with CDDP has been significantly higher for most of the concentrations evaluated compared to individual CDDP treatment. This result is consistent with that obtained in a combination study of manguiferin with CDDP, where it was shown that this combination significantly reduced the percentages of viable cells of CT26, compared with individual treatment with this chemotherapeutic agent [8]. In our study, unlike what was done by Rodríguez and collaborators, we were able to determine the combination index and the dose reduction index; which allow us to know the type of pharmacological interaction between the combined compounds and quantify the dose reduction of each drug to obtain the same effect as the individual treatment. The combination rates were less than 1 for all the concentrations of CDDP and DOX evaluated, that is, there is a synergistic interaction between each of these compounds with the scorpion venom R. junceus. This result is consistent with other studies where they show that there is synergism in the antineoplastic effect of the combination of a natural product with conventional cytostatics [9]; [11]. Curcumin, a non-toxic natural product, can improve the effectiveness of chemotherapeutic drugs used in non-cytotoxic concentrations [22]. The combination of low concentrations of the crude extract of Aloe vera and cisplatin has demonstrated a synergistic effect on growth inhibition compared to agents applied as individual treatment in HeLa and MCF-7 cells of cervical and breast cancer respectively. The combination of Allium atroviolaceum flower extract with DOX, presents synergistic pharmacological interaction resulting in growth inhibitory activity for the different doses evaluated in HeLa tumor cells, compared with the application of the drug as an individual treatment [9]. While, the R. junceus scorpion venom is able to the cytotoxicity, against the HeLa cervical cancer cell line, at low concentrations of the chemotherapeutic drugs 5FU, CDDP and DOX [14]. An additional advantage of the combination of cytotoxic agents with natural products is the reduction of the concentration of the drug, which reduces the toxic effect that causes and avoids the chemo resistance that often causes the ineffectiveness of conventional antitumor therapy [5].

The combination of $\mathrm{R}$. junceus scorpion venom with PTX is synergistic in three of the concentrations evaluated and is antagonistic to the lowest concentrations evaluated of both compounds. These results may seem contradictory to the reports that at low concentrations of cytostatics 5-FU, DOX and CDDP interact synergistically with $\mathrm{R}$. junceus scorpion venom and only antagonistic interactions are observed at high concentrations of cytostatics in the cervical tumor line HeLa [14]. These differences could be because although they are tumor lines of epithelial origin, HeLa differ of CT26 in the specie and histological origin. CT26 is more sensibility than HeLa to the action of $\mathrm{R}$. junceus scorpion venom. Besides, in the study of combination of $R$. junceus scorpion with cytostatics in HeLa, the antagonic interaction was observed at high concentrations of cytostatics combinated with a fixed concentration of $\mathrm{R}$. junceus scorpion venom corresponding to 

cell line

half of IC50 was used and the compounds were combined at reason not constant [14]. However, in the present study, the concentration of the cytostatic was different and R. junceus scorpion venom was combined with conventional cytostatics at a constant rate. Besides, the behavior of which only at high concentrations of the natural product combined with conventional therapy, synergistic interactions are obtained is consistent with the study of combination of resveratrol with 5FU [20].

In this study, it was shown that combinations of the scorpion venom $R$. junceus with PTX, CDDP, DOX increase the cytotoxic effect on the CT26 colon cell line, not only in terms of cell viability, but in terms of morphological changes. Each of the combined treatments evaluated is able to increase the rupture of the cell monolayer, compared to individual treatments. In the groups treated with half of the IC50 of R. junceus venom scorpion, CDDP, DOX, PTX and their combination; the formation of apoptotic bodies, apoptotic nuclei and chromatin condensation was observed by DAPI staining, which provides morphological evidence of the apoptotic potential of this scorpion venom. Previous studies have reported that half of the IC50 of R. junceus scorpion venom causes cell monolayer rupture and morphological changes indicative of cell death due to apoptosis $[12,13]$, similar to what was observed in the present study for the individual and combined treatment of $1 / 2$ IC50 of R. junceus scorpion venom. While, the individual and combined treatment with the IC50 of R. junceus venom with CDDP, DOX, PTX caused morphological changes characteristic of a death due to necrosis and scarce DAPI staining was observed. The measurement of apoptosis is frequently performed by fluorescence microscopy, which shows images of apoptotic bodies and chromatin condensation compared to non-apoptotic control cells [23-25]. Due to its high specificity and availability for quantification, DAPI dye has become the method of choice in nucleus staining because of its ability to significantly detect specific modulations of nuclear morphology during apoptosis [26].

In the present study was observed that both the individual treatment of cisplatin and the combination of venom and DOX did not show morphological features through DAPI staining that were suggestive of the occurrence of apoptosis, which suggests that it can induce cell death by necroptosis Several authors recognize that CDDP is capable of inducing cell death by necrosis in several tumor cells; Such is the case of the KYSE140 squamous cell carcinoma of the esophagus [27]. The scorpion venom R. junceus added at concentrations 1.5 times higher than the IC50, induces cell death by necrosis in tumor cells of different histological origin which was evidenced by fluorescence microscopy [12]. Given these evidences, the occurrence of apoptosis and necrosis in different cell types suggest that the action of $\mathrm{R}$. junceus scorpion venom on tumor cells is not produced by a single event; in which cell intrinsic factors and extrinsic factors such as the concentration of venom in the incubation medium could be involved [12]. In this context it is valid to point out that the scorpion venom is constituted by a mixture of components whose relative concentrations can cause the occurrence of each of these events depending on the concentration added. Therefore, the ability of R. junceus scorpion venom to induce both cell death events could represent an interesting alternative for the treatment not only of sensitive cancers but of those resistant to conventional therapies [12].

As a general rule, the design of combinations that include a traditional chemotherapy drug, plus one or more natural bioactive compounds, constitutes a promising approach to achieve potential improvements in the partial development or complete remission of the CRC [28,29]. The results obtained in this work confirm the potential of individual treatment and combined with conventional chemotherapy of $R$. junceus scorpion venom for the treatment of cancer. In addition, this combination could reduce the adverse effects of conventional therapy by significantly reduce their doses to obtain the same effect as individual therapy. The type of drug interaction could be dependent or independent of the concentration of the drugs evaluated; as well as the type of cell line. This work, for the first time brings us closer to the type of cell death, specifically to the knowledge of the morphological changes that are induced with the combination of $\mathrm{R}$. junceus scorpion venom with conventional cytostatics; Even the effect of IC50 on cell death events is evaluated for the first time. In addition, we confirm that the effect of $\mathrm{R}$. junceus scorpion venom on tumor cells is not produced by a single cell death event; which we would have to deepen in future studies.

\section{Conclusions}

$R$. junceus scorpion venom is able to increase synergistically in vitro, the cytotoxicity in CT26 colon cancer of the CDDP and DOX chemotherapeutic drugs, regardless of their concentration. The synergism and antagonism observed in the combination of $\mathrm{R}$. junceus scorpion venom with PTX on the viability of CT26 colon cancer, is dependent on its concentration.

Individual and combined treatment, at low concentrations, of the scorpion venom $R$. junceus scorpion venom with conventional cytostatics induces morphological changes suggestive of cell death by apoptosis. At high concentrations of the individual and combined treatment of the scorpion venom R. junceus scorpion with conventional cytostatics, morphological changes characteristic of cell death due to necrosis are observed.

\section{Acknowledgments}

The authors would like to thank to personal from cell culture service laboratory of Tropical Medicine Institute "Pedro Kourí” by the support for cell culture maintenance.

\section{Funding}

Authors confirm that this research did not receive any specific grant from funding agencies in the public, commercial, or notfor-profit sectors. 


\section{References}

1. Moradi M, Solgi R, Vazirianzadeh B, et al. Scorpion venom and its components as new pharmaceutical aproach to cancer treatment, a systematic review. Int J Pharmaceut Sci Res. 2018; 9: 2604-15.

2. Rademaker, Costanza, Bellier, Herfs, Peiffer, Agirman. Human colon cancer cells highly express myoferlin to maintain a fit mitochondrial network and escape p53-driven apoptosis. Oncogenesis. 2019; 8:1-13.

3. Alaufi OM, Noorwali A, Zahran F, et al. Cytotoxicity of thymoquinone alone or in combination with cisplatin (CDDP) against oral squamous cell carcinoma in vitro. Sci Rep. 2017; 7:1-15.

4. Focaccetti C, Bruno A, Magnani E, et al. Effects of 5fluorouracil on morphology, cell cycle, proliferation, apoptosis, autophagy and ROS productions in endothelial cells and cardiomyocites. PloS One. 2015; 10.

5. Suvarna V, Murahari M, Khan T, et al. Phytochemicals and pi3k inhibitors in cancer-an insight. Front Pharmacol. 2017; 8: 1-23.

6. Zhang YP, Li YQ, Lv YT, et al. Efecto de la curcumina sobre la proliferación, la apoptosis, la migración y la invasión de células A375 de melanoma humano. Gineta Mol Res. 2015; 14: 1056-67.

7. Benarba A, Pandiella B. Colorrectal cancer and medicinal plants: Principle findings from recent studies. Biomed Pharmacoth. 2018; 107:408-423.

8. Rodríguez JC, Rodeiro I, Delgado R, et al. Evaluation of combination treatment effect of mangiferin with cisplatin and 5-fluorouracil in CT26.WT and CKO-K1 cells. Revista Cubana de Farmacia. 2014;48: 658-71.

9. Khazaei S, Ramachandran V, Abdul R, et al. Flower extract of Allium atroviolaceum triggered apoptosis, activated caspase- 3 and down-regulated antiapoptotic Bcl-2 gene in HeLa cancer cell line. Biomed Pharmacoth. 2017; 89: 1216-26.

10. Benarba A, Pandiella B. Colorrectal cancer and medicinal plants: Principle findings from recent studies. Biomed Pharmacoth. 2018; 107:408-423.

11. Rejhova A, Opattova A, Cumov A, et al. Natural compounds and combination therapy in colorrectal cancer treatment. Eur J Med Chem. 2018; 144: 582-94.

12. Díaz-García A, Morier-Díaz L, Frión-Herrera Y, et al. In vitro anticancer effect of venom from Cuban scorpion Rhopalurus junceus against a panel of human cancer cell lines. J Venom Res. 2013; 4:5-12.

13. Díaz-García A, Ruiz-Fuentes JL, Rodríguez-Sánchez H, et al. Rhopalurus junceus scorpion venom induces apoptosis in the triple negative human breast cancer cell line MDAMB231. J Venom Res. 2017; 8:9-13.

14. Yglesias-Rivera A, Rodríguez-Sánchez H, Díaz-García A. Synergistic effect of Rhopalurus junceus scorpion venom combined with conventional cytostatics in cervical cancer cell line HeLa. J Pharmacy Pharmaco Res. 2019; 7: 67-76.
15. Yaqoob R, Tahir H, Arshad M, et al. Optimization of the conditions for maximum recovery of venom from scorpions by electrical stimulation. Pakistan J Zool. 2016; 48: 265-9

16. Tobassum S, Thair Hm, Zhaid MT, et al. Effect of milking method, diet, and temperature on venom production in scorpions. J Insect Sci. 2018;18-4.

17. Herrera Y, Heras N, Cardoso D. Adaptation to microplates and validation of the Lowry technique. VacciMonitor. 1999; 3: 7-11.

18. Chou TC. Theoretical basis, experimental design, and computerized simulation of synergism and antagonism in drug combination studies. Pharmacol Rev. 2006; 58:62181 .

19. Mosmann T. Rapid colorimetric assay for cellular grow and survival: application to proliferation and citotoxicity assays. J Immunol Meth. 1983; 65: 55-63

20. Moradi N, Amini S, Tanzadehpanah E, et al. Remarkable apoptotic pathway of Hemiscorpius lepturus scorpion venom on CT26 cell line. Cell Biol Toxicol. 2019; 10:1-13.

21. Przybyszewska M, Miłoszewska J, Kotlarz A, et al. Imatinib inhibits the renewal and tumorigenicity of ct-26 colon cancer cells after cytoreductive treatment with doxorubicin. Arch Immunol Ther Exp (Warsz). 2017; 65: 51-67.

22. Vinod B, Maliekal T. Phytochemicals as chemosensitizers: from molecular mechanism to clinical significance. Antioxid Redox Signal. 2013; 18: 1307-48.

23. Mohan A, Narayanan S, Sethuraman S, et al. Novel resveratrol and 5-fluorouracil coencapsulated in pegylated nanoliposomes improve chemotherapeutic efficacy of combination against head and neck squamous cell carcinoma. BioMed Res Int. 2014; 2014:424239

24. Saha SK, Sikdar S, Mukherjee A, et al. Ethanolic extract of the Goldenseal, Hydrastis canadensis, has demonstrable chemopreventive effects on HeLa cells in vitro: Drug-DNA interaction with calf thymus DNA as target. Environ Toxicol Pharmacol. 2013; 36: 202-214.

25. Ansil PN, Wills PJ, Varun R, et al. Cytotoxic and apoptotic activities of Amorphophallus campanulatus (Roxb.) B1. tuber extracts against human colon carcinoma cell line HCT-15. Saudi J Biol Sci. 2014; 21: 524-531.

26. Mandelkow R, Gümbel D, Ahrend H, et al. Detection and quantification of nuclear morphology changes in apoptotic cells by fluorescence microscopy and subsequent analysis of visualized fluorescent signals. Anticancer Res. 2017; 37: 2239-2244.

27. Xu Y, Lin Z, Zhao N, et al. Receptor interactive protein kinase 3 promotes cisplatin-triggered necrosis in apoptosisresistant esophageal squamous cell carcinoma cells. PLoS ONE. 2014; 9: e100127.

28. Guamán-Ortiz LM, Ramirez MIE. Natural compounds as modulators of non-apoptotic cell death in cancer cells. Curr Genomics. 2017; 18: 132-155.

29. Rodríguez JC, Rodeiro I, Delgado R, et al. Evaluation of combination treatment effect of mangiferin with cisplatin 
Synergism of the combination of Rhopalurus junceus scorpion venom with conventional cytostatics in the ct26 tumor cell line

and 5-fluorouracil in CT26.WT and CKO-K1 cells. Revista Cubana de Farmacia. 2014;48: 658-71.

\section{*Correspondence to}

Arianna Yglesias-Rivera

Laboratories of Biopharmaceuticals and Chemicals

Productions

Havana, Cuba

E-mail: ariannayglesias@gmail.com 